\title{
Typologies of Strategies used by the University of the Philippines College of Dentistry Clinicians in Teaching Patients in Periodontics
}

\author{
Bhabita V. Murjani \\ College of Dentistry, University of the Philippines Manila
}

\begin{abstract}
Although patient education is performed regularly, the impact of how it is done is usually taken for granted. Observing dental students as they educate their patients may provide a glimpse of how dentists educate their patients in actual practice.
\end{abstract}

Objective. The main objective of this study is to describe the various teaching strategies used by graduating dental clinicians in educating patients.

Methods. This study documents 47 patient encounters in the Oral Medicine Section of the University of the Philippines College of Dentistry (UPCD). The Grounded Theory Qualitative Design was used. Naturalistic observation was employed, maximum purposive sampling was done, and data was continuously collected until saturation point was reached. Documentation was performed through field notes, video recording of encounters, and patient interview. Potential categories were tried out and created until a fit between data and theory was achieved. Constant comparison of recurring patterns in the manner of teaching about plaque and its prevention, particularly in three elements in the learning process as described by Gagne, namely, motivation, stimulation, and patient involvement, were observed and grouped to form generalizations. Typologies were then developed.

Results. Four types of teaching strategies emerged from the study: the prescriptive, the elaborative, the responsive, and the evaluative. Though combinations of strategies were employed in each teaching element, the prescriptive approach emerged as the most dominant.

Conclusion. The majority of UPCD clinicians appear to be concrete explainers who only provide information and factual knowledge to patients, thereby restricting their patients' level of learning to mere recall.

Key Words: patient education strategies, grounded theory, typologies

Corresponding author: Bhabita V. Murjani, DDM, MHPEd

College of Dentistry

University of the Philippines Manila

Pedro Gil corner Taft Avenue, Ermita, Manila 1000 Philippines

Telephone: +632 3023983 local 119

Fax No: +632 3203983 local 103

Email: bette@murjani.ph
Introduction

The president of a dental consulting firm in the U.S. aptly stated the significance of patient education by saying that "Patient Education is the Profession's greatest commission." 1 Patient education plays a major role in the promotion of oral health and disease prevention. The occurrence of many oral disorders such as caries and periodontal disease can be avoided if dentists explain to their patients the causes of their disease and discuss with them the importance of improving dietary habits and maintaining good oral hygiene. ${ }^{2}$ A patient who is involved, informed, and committed is the key to successful treatment. ${ }^{3}$ Teaching a patient, however, goes beyond merely providing a set of brochures and reading materials. Active participation by the dentist is also necessary because it exerts a great influence on the patient's attitudes regarding oral health. In order for patients to improve their awareness of the importance of oral health care, they need to change their disposition and perception about it. This change would most likely occur if patients are informed about the various things that can happen within the oral cavity-including how damage may be repaired and how the progression of oral disease may be curtailed. The World Health Organization states that education for health is "aimed at encouraging people to want to be healthy, to know how to stay healthy, to do what they can individually and collectively do to maintain health and to seek help as needed."4

Green defines health education as "any combination of learning opportunities designed to facilitate voluntary adaptations of behavior which are conducive to health."2 This involves providing purposeful activities that would stimulate the patient and prompt a response in the form of change in behavior, leading to improved oral health status.

The benefits of patient education cannot be overemphasized. An educated patient is one who is more likely to return for treatment, comply with instructions, and be more conscientious about maintaining a healthy oral cavity. This would result in disease prevention and increased patient satisfaction. As Newsome puts it, "The satisfied customer is an indispensable means of creating a sustainable advantage in the competitive environment in the 1990s." ${ }^{5}$ Patients who are successfully educated appreciate the efforts of the dentist and build a stronger relationship with them. Patients usually evaluate their dentists based on 
how they have been treated and not merely on the treatment outcome. Ultimately, this would be the basis of patient satisfaction and compliance which will eventually motivate their return. ${ }^{6}$

Thus, it is important that dentists be able to teach their patients. It must be taken into consideration, however, that a teaching activity has to be significant to the learner for it to be effective. It is only when a personal meaning is established that the new experience can be accepted and a willful response be elicited. Thus, the manner of educating patients should not be generic. The stimulus must have enough impact on the patient in order to trigger change. It should not be based on a single strategy or formula. Instead, varying methods and styles congruent to the learning objective and in line with the learner's characteristics should be employed to ensure that learning would take place. Hanson and Pichert remind us that patient education is an interactive process and emphasize the importance of patient involvement in the whole learning process. All these should therefore be considered when dental professionals teach their patients. ${ }^{7}$ Keef states that "each learner has distinct and consistent preferred ways of perception, organization, and retention. These learning styles are characteristic cognitive, affective and physiological behaviors that serve as relatively stable indicators of how learners perceive, interact with and respond to learning environment." 8 As Gropper has stated, "Instruction will become optimally effective only when treatments are attuned to individual differences among learners. Treatments can be selected which will be responsive to the needs of the individual learners based on already assessed characteristics." ${ }^{\prime 9}$ Rodney et al. remind us that though all health care providers are educators of patients, only a few prepare for the role. However, it is important that health professionals be effective teachers if the goal is to bring forth changes in patients' knowledge and behavior. ${ }^{10}$

The objective of this study is to determine and describe the typology of teaching strategies employed by senior clinicians from the University of the Philippines in educating their patients about plaque and its prevention. The patient education process was divided into three elements using the basic elements of teaching developed by Gagne, namely motivation, stimulation and involvement. In any teachinglearning activity, certain principles and components are basic for its effectiveness. Gagne discusses how teaching should be congruent with the process of learning. ${ }^{11}$ Thus, activities that will influence each phase of learning should be formulated. For an individual to learn, he must first and foremost be motivated. The motivated learner should then be given information in a manner which is stimulating, allowing for a learning incident to be stored, and later on retrieved. Learning continues as the concepts are contextualized and applied. Activities that will provide opportunities for application and performance should thus be incorporated. Teachers must decide on what the students should learn, the experiences necessary for attainment of objectives, and the resources needed. Once a new performance is presented, feedback should be provided and finally, the "learning loop" is closed as reinforcement is given. ${ }^{11}$ Meanwhile, Ferris and Winslow, ${ }^{12}$ Locker, $^{2}$ Jameson, ${ }^{1}$ and Roth ${ }^{6}$ explain the importance of motivation, stimulation, and patient involvement as basic elements for effective patient education.

This study attempts to investigate the manner in which dentists in the Philippines educate their patients. Since observing actual patient-dentist interactions has inherent logistical and ethical difficulties, student (clinician)-patient interactions were observed instead. According to Bandaranayake, the foundation for later learning is provided in earlier learning. Thus, the manner in which dentists educate their patients is greatly influenced by training acquired in the university. A university's curricular program on patient education, whether implicit or explicit, plays a crucial role in honing the teaching skills of students. Usually, the methods employed while in the University are carried into private practice. ${ }^{13}$

Observing the actual practice of students as they educate their patients provides a glimpse of strategies employed by dentists in actual practice. Reflecting on these typologies could initiate self-assessment which would propel one towards self-improvement. The practice of the profession entails continuous learning and enhancement, not only in knowledge and skills in preserving and restoring the oral cavity but in communication and education as well.

\section{Materials and Methods}

\section{Research design}

A descriptive qualitative research design, specifically the Grounded Theory Qualitative design, was employed in this study. In this design, "the researchers intended to generate a theory that was grounded in data systematically gathered and analyzed."14 The theory was allowed to emerge and was formed inductively as data were gathered and analyzed. Data were repeatedly viewed and analyzed until recurring characteristics emerged. These were then clustered, classified and described. Patton aptly stated that in Grounded Theory, "the evaluator's task is to generate program theory from holistic data gathered through naturalistic inquiry for the purpose of helping program staff and decision makers."15 Thus, the researcher simply gathered observations without bias and generated conclusions based on the data acquired.

Since the objective of this study was to describe various strategies employed by the senior clinicians in educating patients, the emphasis was on the quality of the activity as it occurred in its actual setting. As the researcher collected and analyzed the data, general patterns began to emerge 
regarding the strategies employed by the students as they educated their students. All events that occurred as the clinicians educated the patients were deemed necessary and were therefore documented. The subject of interest was the clinician - the manner by which he taught patients (how he explains, communicates, interacts, contextualizes, answers queries etc).

\section{Data collection procedure and instruments}

Observation provides a rich source of data about how events actually transpire. It also supplies a pool of answers to particular questions. In this study, naturalistic observation was employed as the primary method of data collection. The researcher, together with two observers, noted occurrences in their natural setting without an attempt to control any variables. The regular senior clinicians were observed at their regular shifts, specifically while treating patients for scaling and/or root planing. In the actual clinical education process, motivation was observed as diagnosis was presented to the patient and the general treatment goal was laid down. Stimulation, on the other hand was observed as oral hygiene and oral health care instructions were conveyed to the patient since it was at this point that a variety of teaching aids were employed by the clinicians and demonstration transpired. Patient involvement was noted as patient interaction and feedback transpired.

Forty-nine patient encounters among twelve clinicians were observed and recorded. To comply with ethical requirements, the researcher obtained official consent from the administration of the college for observation and videotaping. Consent from both the patients and the clinicians were also obtained prior to observing and recording. Of the 49 encounters, four each were obtained from eight clinicians, three encounters each from Clinician 5 (C5) and Clinician 7 (C7), five encounters from Clinician 10 (C10) and six encounters from Clinician 9 (C9). Saturation was noted after these encounters were obtained; thus, data collection was terminated thereafter. Unfortunately, the audio recordings of one encounter each from C5 and C7 were unclear and had to be voided; thus, the total number of encounters studied was 47. For maximum purposive sampling, data was continuously collected until saturation point was reached (see sampling method). The interactions recorded were firsttime patient encounters and not second visits. According to literature, a thorough patient education should transpire during initial visits, and is only followed up by simple reinforcement at succeeding visits. Since several first-time patient encounters occurred at one instance, it was important to have additional help in order to ensure that ample encounters were captured. Thus, additional observers who were graduates of the same field, were hired. The researcher, being a clinical supervisor of the University, assumed the role of an "observer - as participant." Though part of the group, the researcher made it clear that she was a mere observer during the period of observation and the data gathered had no weight in the evaluation of student performance. One hired observer (the internal observer) was a recent graduate of the University, while the other (the external observer) was a licensed dentist that graduated from another university. The former had access to students and knew the set up. The latter had a fresh outlook on the process and the environment. They both played the role of complete observers, not being part of the clinical setting in any way. Each clinician was observed by either two or three of the observers.

Documentation of the actual observation and interactions between patient and clinician was done through field notes which were jotted down on observational forms to facilitate data collection and analysis. To increase validity and reliability, the patient-clinician encounters were also videotaped. The researcher and the hired observers were at different cubicles at each instance so as to have a greater number of encounters per day. The goal was to study several patient encounters of a single clinician, and to study several clinicians in a day.

To further ensure that data was objectively recorded and analyzed, interviews with patients were included in the data collection process. In instances where an incident or encounter needed clarification, the patients were approached for an informal interview. The patients were questioned either when the clinician left to call on the faculty for checking, or right before being dismissed.

\section{Sample and sampling method}

The subjects chosen for this study were UP College of Dentistry senior clinicians, since they were more experienced and had eliminated fear from first-time handling of patients. Sampling was done purposively among the regular senior clinicians. There were 44 clinicians divided into three groups. Among these, only four were male and the rest were female. The clinicians were 22 to 24 years old. All of them were in the sixth level of dentistry and had satisfactorily completed the basic courses.

Each group rotated for 5 weeks in a certain section. There were three sections of rotation, namely, Operative Dentistry, Oral Medicine, and Prosthodontics. The clinicians were observed as they shifted to the Oral Medicine section since this was where patient education on plaque was most expected to transpire. The teaching styles employed by the clinicians upon patient education were observed. All variations presented were identified and the clinical encounters were categorized based on common existing patterns. Unique or diverse variations were also included. The maximum variation sampling, a purposive sampling strategy, was therefore the appropriate sampling strategy for this study. However, it was important that the data were continuously collected until saturation point was reached. This refers to the point at which observations have become 
similar to previous observations, or succeeding encounters have become repetitive. For validity and reliability, several patient-clinician interactions were observed for every senior clinician.

\section{Data Analysis}

The focus of the analysis was to determine the different strategies employed by clinicians in educating their patients. The goal was to formulate classifications based on interrelations of the various strategies employed by the clinicians with emphasis on the basic elements of teaching.

Videotapes of the interactions were viewed and field notes were edited. Recurring consistencies and irregularities were noted among clinicians through the use of colored markers and post-its. The areas of focus were limited to the teaching elements discussed by Gagne, namely, motivation, stimulation, and patient involvement. The recurring consistencies were then clustered together, summarized, described, and labeled according to the dominant features per cluster. All possibilities presented by the data were included. Interrelations of various categories were then analyzed to formulate typologies on the teaching strategies employed. Thus, a Constant Comparison/Grounded Theory data analysis method was employed in this study. In this approach, a constant interplay exists between the researcher and the data as potential categories are tried out and created until a fit between data and theory is achieved. ${ }^{15}$ As data were analyzed, comparisons were made and dominant observable features were grouped to form generalizations.

\section{Results}

During motivation, the clinicians conveyed to the patients the existing condition of the periodontium. The specific diagnosis was either mentioned by name or merely described-for example as "namamaga yung gilagid" (the gums are swollen). It was also at this point that the cause for the disease was communicated to the patient, at times with the aid of illustrations in a flipchart, and/or a face mirror that reflected the patient's oral cavity. Stimulation was observed when the clinicians demonstrated brushing techniques and the proper use of interproximal adjuncts through a model articulator, use of hand gestures or actual demonstration on the patient. Instructions on oral health care such as frequency and duration of brushing and flossing and frequency of dental visits were also given to the patient. Patient involvement included asking questions and probing the patient's oral health practices as well as requesting a demonstration of the patients' actual brushing technique on a model articulator. Also included were: a return demonstration after the proper technique of brushing and flossing was taught, eliciting questions from the patients on oral hygiene techniques.

Four types of strategies emerged and were labeled according to the dominant characteristics presented in each cluster (Table 1).

\section{No patient education}

Conversations, verbal or non-verbal cues regarding the cause and prevention of plaque and the current periodontal disease of the patient were absent.

Two encounters from one clinician (C8) had no patient education. During these encounters, the clinician directly proceeded to scaling and polishing after diagnosis and charting, after which the clinician reminded the patient that a second appointment was needed. The patients were then dismissed.

\section{The prescriptive approach}

The clinician relayed facts with minimal or no explanation. The clinician seemed to be concerned mainly

Table 1. Summary of the Typologies of teaching strategies in educating a patient in periodontics

\begin{tabular}{|c|c|c|c|c|}
\hline \multirow{2}{*}{$\begin{array}{c}\text { Basic Elements in } \\
\text { Teaching }\end{array}$} & \multicolumn{4}{|c|}{ Typologies of Teaching Strategies } \\
\hline & Prescriptive & Elaborative & Responsive & Evaluative \\
\hline $\begin{array}{l}\text { Motivation } \\
\text { (diagnosis to } \\
\text { treatment plan) }\end{array}$ & $\begin{array}{l}\text { Stipulative presentation of the } \\
\text { diagnosis, cause of the condition } \\
\text { and treatment goals }\end{array}$ & $\begin{array}{l}\text { Descriptive and explanatory } \\
\text { presentation of the diagnosis, } \\
\text { cause of the condition and } \\
\text { treatment goals }\end{array}$ & $\begin{array}{l}\text { Descriptive, explanatory, } \\
\text { individualized \& contextualized } \\
\text { presentation of the diagnosis, } \\
\text { cause of the condition and } \\
\text { treatment goals }\end{array}$ & $\begin{array}{l}\text { (No such approach was } \\
\text { presented in this element } \\
\text { of teaching) }\end{array}$ \\
\hline $\begin{array}{l}\text { Stimulation } \\
\text { (oral hygiene and } \\
\text { oral health care) }\end{array}$ & $\begin{array}{l}\text { Sequential demonstration of } \\
\text { oral health care procedures } \\
\text { without commentaries }\end{array}$ & $\begin{array}{l}\text { Sequential demonstration, } \\
\text { with explanation, of the oral } \\
\text { health care procedures }\end{array}$ & $\begin{array}{l}\text { Sequential demonstration with } \\
\text { explanation \& customization of } \\
\text { the oral health care procedures }\end{array}$ & $\begin{array}{l}\text { (No such approach was } \\
\text { presented in this element } \\
\text { of teaching) }\end{array}$ \\
\hline $\begin{array}{l}\text { Patient Involvement } \\
\text { (questioning and } \\
\text { return demo on oral } \\
\text { hygiene techniques) }\end{array}$ & $\begin{array}{l}\text { Engaging the patient through } \\
\text { asking general questions or } \\
\text { requesting the patient to merely } \\
\text { show his/her oral hygiene } \\
\text { technique through a model } \\
\text { articulator }\end{array}$ & $\begin{array}{l}\text { (No such approach was } \\
\text { presented in this element of } \\
\text { teaching) }\end{array}$ & $\begin{array}{l}\text { Engaging the patient by detailed } \\
\text { questioning on the patient's } \\
\text { existing condition; or requesting } \\
\text { the patient to simultaneously } \\
\text { perform the oral hygiene } \\
\text { procedure on his/her own } \\
\text { dentition, while it is being taught }\end{array}$ & $\begin{array}{l}\text { Engaging the patient by } \\
\text { requesting for a return } \\
\text { demonstration of an oral } \\
\text { hygiene procedure taught, } \\
\text { and providing feedback to } \\
\text { the patient. }\end{array}$ \\
\hline
\end{tabular}


with simply telling the patient the diagnosis and oral health maintenance instructions. The clinician provided the necessary data without expounding. The clinician dictated, laying down rules, directions, and guidelines, and exerting authority.

Forty out of the 45 encounters with patient education utilized the prescriptive approach at some point in the process.

\section{The elaborative approach}

The clinicians gave more than just the diagnosis and instructions regarding oral health care. Information was expounded upon by explaining procedures and presenting links among various concepts. Demonstration was fragmented and the rationale for the sequential procedures was supplied. The patients were therefore told not just what to do, but how and why it should be done.

This approach was observed in 29 of the 45 patientclinician encounters.

\section{The responsive approach}

Explanations were given, the explanations contextualized to the patient's specific condition. The information or the demonstration was elaborated upon and modified according to the identifiable needs of the patient. While explaining the diagnosis, the clinician referred to the condition of the patient's oral cavity. Instructions and rationale for sequential procedures for oral health care were not just stated but were also adapted to the patient's specific situation.

This approach was observed in 25 of the encounters.

\section{The evaluative approach}

The importance of feedback was recognized. This went beyond expounding relevant information about the patient's condition. This included questioning the patient and eliciting feedback regarding the patient's understanding of the initiation and progression of the disease (element of motivation). In addition to this was questioning patient's understanding of the relevance of the oral hygiene practices (element of stimulation). Lastly, after the clinician demonstrated oral health care procedures, e.g. brushing and flossing, feedback was gathered from the patient regarding the actual oral hygiene technique, either through questioning or through a return demonstration of a procedure (element of patient involvement). The clinician then further affirmed or corrected the patient.

This was observed in only eight of the encounters.

Based on evidence presented through the existing data acquired in the naturalistic observation of 47 patientclinician encounters, almost all clinicians performed patient education in periodontics, using a variety of teaching aids throughout the process, using a flipchart, book, model articulator, mirror, actual material (dental floss), and even the patient's own teeth. These encounters ranged from 2 to 15 minutes.

The strategy most often used was the prescriptive approach. However, the percentage of use for these approaches was different in the elements of motivation and stimulation (Table 2 and Figure 1). In motivation, the prescriptive approach was dominant in $33.3 \%$ of the encounters. The elaborative and responsive approaches were not far behind and had close figures. The former was dominant in $22.2 \%$ of the encounters while the latter in $20 \%$ of the encounters. In stimulation, the prescriptive approach was dominant in $57.78 \%$ of the encounters. The responsive approach was dominant in $11.11 \%$ of the encounters while the elaborative approach was dominant in $6.67 \%$ of the encounters. In addition, these figures reveal that the clinicians had employed a more varied teaching style in the presentation of the cause and treatment goals of a patient's condition than in the presentation of oral health care instructions and maintenance.

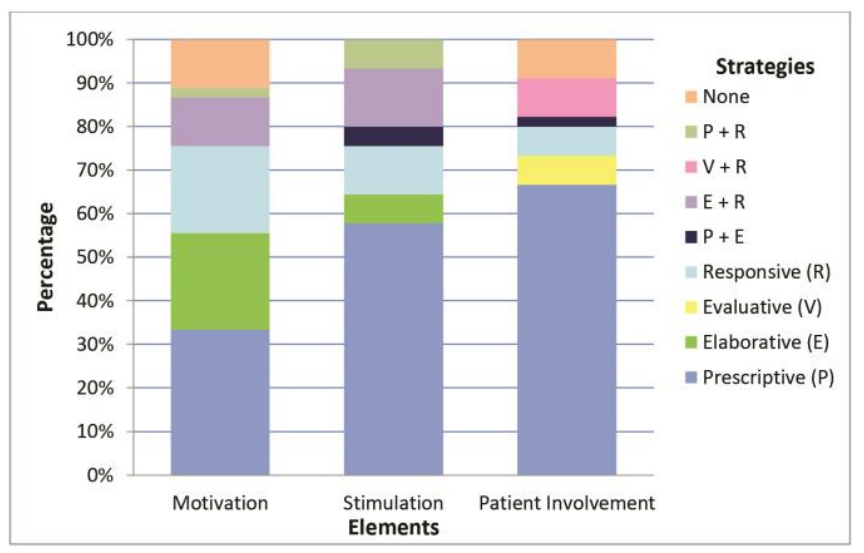

Figure 1. Comparison of Strategies Used in Patient Education Process

Table 2. Distribution of elements of the process of patient education in different strategies employed by the clinicians in UPCD, 2005.

\begin{tabular}{crrrrrr}
\hline & \multicolumn{6}{c}{ Elements } \\
\cline { 2 - 7 } Strategies & \multicolumn{2}{c}{ Motivation } & \multicolumn{2}{c}{ Stimulation } & \multicolumn{2}{c}{$\begin{array}{c}\text { Patient } \\
\text { Involvement }\end{array}$} \\
\cline { 2 - 7 } & $\begin{array}{c}\text { No. of } \\
\text { Encounter }\end{array}$ & $\%$ & $\begin{array}{c}\text { No. of } \\
\text { Encounter }\end{array}$ & $\%$ & $\begin{array}{c}\text { No. of } \\
\text { Encounter }\end{array}$ & $\%$ \\
\hline Prescriptive (P) & 15 & 33.33 & 26 & 57.78 & 30 & 66.67 \\
Elaborative (E) & 10 & 22.22 & 3 & 6.67 & & \\
Evaluative (V) & 0 & 0 & 0 & 0 & 3 & 6.67 \\
Responsive (R) & 9 & 20 & 5 & 11.11 & 3 & 6.67 \\
Combined & & & & & & \\
P+E & 0 & 0 & 2 & 4.44 & 1 & 2.22 \\
E + R & 5 & 11.11 & 6 & 13.33 & 0 & 0 \\
V +R & 0 & 0 & 0 & 0 & 4 & 8.89 \\
P + R & 1 & 2.22 & 3 & 6.67 & 0 & 0 \\
[-pNone & 5 & 11.11 & 0 & 0 & 4 & 8.89 \\
Total & 45 & $\mathbf{1 0 0}$ & $\mathbf{4 5}$ & $\mathbf{1 0 0}$ & $\mathbf{4 5}$ & $\mathbf{1 0 0}$ \\
\hline
\end{tabular}


In $66.67 \%$ of the encounters, patients were involved by merely being asked to answer simple questions and demonstrate their brushing technique through a model articulator. The responsive approach was dominant in $6.67 \%$, and the evaluative approach was dominant in $6.67 \%$. Patient involvement was absent in four of the encounters. It is noteworthy that the evaluative approach was evident only in patient involvement.

\section{Discussion}

In this study, the clinicians appear to be concrete explainers, meaning there is an attempt at concretizing information to the patient, by means of visual aids, if not by verbal explanations. According to Locker, ${ }^{2}$ the simplest approach to patient education is providing information on threats to oral health and providing skills necessary to avoid or cope with these threats. Health professionals should, however, go beyond merely providing information. The aim, therefore, is to make the patient understand his role in the whole treatment process and maintenance of health. Thus, dentists should not merely tell patients what they should do and expect them to do it. ${ }^{1}$ The expected outcome is a patient who is convinced that changes in habits are necessary and who is willing to enact these changes. Teaching patients is viewed as "any interpersonal influence aimed at changing the way in which another person can or will behave." 1 This can be more readily achieved if the patient is made an active participant in the whole process and not just a spectator. According to Rodney et al., the patient's involvement in the health care process is essential. This can only be achieved through effective patient education. ${ }^{10}$

The next dominant approach employed in both motivation and stimulation is the elaborative. In the elaborative approach, conceptual knowledge is supplied, wherein rationales, as well as links to concepts in the diagnosis, treatment goals, and oral health care instructions are given to the patient.

A noteworthy insight from this qualitative research is that the approaches, when paralleled with the twodimensional taxonomy of cognitive domain presented by Anderson et al., present a hierarchical nature. ${ }^{16}$ The various approaches promote different levels of cognitive learning and provide different types of knowledge to the patient. In the prescriptive approach, for instance, the patient is given information that is simply to be stored in the patient's memory and is thus brought to the first level in the cognitive taxonomy of learning, which is remembering.

In the elaborative approach, the patient is brought to a level of understanding. The responsive approach provides an opportunity for application and analysis on the part of the learner. The patient is not just given generic explanations of the disease and oral health care but specific information regarding his existing condition. Finally, the evaluative approach gives the learner an opportunity to perform and feedback is given. The degree by which the patient has learned is determined and necessary correction and reinforcement is provided. This allows more effective analysis and application of the procedure and allows reflection on their level of awareness and ability to assess the procedure they would perform. Thus, to a certain degree, metacognitive knowledge is supplied. Table 3 provides a summary of this.

Very few clinicians bring their patients to a higher level of learning and more appear to impart knowledge more than skills and attitude. There is emphasis in providing information rather than developing patients' skills and attitude in oral health care and maintenance.

In a study by Hanson et al., patient involvement was cited as one of the instructional elements that are relevant to patient education. ${ }^{7}$ Findings in their analysis of 27 patient education experiments revealed that patients given more opportunity to be more involved in the learning outperformed those less involved. "Learning will be maximized as the proportion of time in which the patient is actively involved in the instruction increases."

Based on the concepts and principles mentioned, effective patient education would ensue if the responsive and evaluative approaches are employed.

\section{Conclusions}

There were four basic strategies employed by the clinicians in patient education in periodontics, namely, the prescriptive, the elaborative, the responsive, and the evaluative approaches. The first three were evident in the elements of motivation and stimulation. The strategies employed in patient involvement were prescriptive, responsive, and evaluative. In most encounters, combinations of strategies were employed in each element of

Table 3. Taxonomy of Cognitive Domain of Learning

\begin{tabular}{|c|c|c|c|c|c|c|}
\hline \multirow{2}{*}{$\begin{array}{l}\text { THE KNOWLEDGE } \\
\text { DIMENSION }\end{array}$} & \multicolumn{6}{|c|}{ THE COGNITIVE PROCESS DIMENSION } \\
\hline & Remember & Understand & Apply & Analyze & Evaluate & Create \\
\hline Factual Knowledge & Prescriptive & & & & & \\
\hline Conceptual Knowledge & & Elaborative & Responsive & Responsive & & \\
\hline Procedural Knowledge & & Elaborative & Responsive & Responsive & & \\
\hline Metacognitive Knowledge & & & $\begin{array}{l}\text { Responsive } \\
\text { Evaluative }\end{array}$ & $\begin{array}{l}\text { Responsive } \\
\text { Evaluative }\end{array}$ & Evaluative & \\
\hline
\end{tabular}


teaching. However, the dominance of a certain strategy was evident. The dominant strategy employed in the encounters, in both elements of motivation and stimulation, was the prescriptive approach, followed by the elaborative approach and lastly the responsive approach. The evaluative approach was limited to patient involvement. Patients were mostly involved in the process of learning through the prescriptive approach, although combinations of the typologies were employed in each patient encounter.

As this paper provides an insight on how clinicians educate their patients with regards to plaque, its consequences, and possible means of prevention, it gives practicing dentists an opportunity to reflect on how patient education transpires in their respective clinics and how it could be further improved to achieve a change of attitude and behavior on the patient. By knowing the four typologies employed in patient education, the dentist can purposefully create teaching-learning encounters of a higher level of learning that would be vital to successful treatment.

A study on dental practitioners engaged in private practice would be ideal but would have many logistical and ethical considerations. Instead, the same study could be done with a greater number of clinicians and patientclinician encounters. In addition, including other disciplines as well as other institutions would definitely provide more data that could be used to verify the present findings as well as provide new insight.

\section{References}

1. Jameson C. Patient Education: The Profession's Greatest Commission. Dent Today. 1998; 17(3):128-9, 137.

2. Locker D. An Introduction to behavioral science \& dentistry. London: Routledge; 1998.

3. Corn H, Marks M, Corn B. Educating the patient in effective plaque control. In: J.W. Clark, ed. Clark's Clinical Dentistry. J.B. Lippincott Company; 1987. pp. 1-4 (Original work published in 1976).

4. Irvine S. Preparing students for a consumer education role. In: Cox, KR, Ewan CE, eds. Medical Teacher, $2^{\text {nd }}$ Ed. New York: Churchill Livingstone; 1988. pp. 132-133.

5. Newsome PR, Wright GH. A review of patient satisfaction: Concepts of satisfaction. Br Dent J. 1999; 186(4 Spec No):161-5.

6. Roth S. Tools every dentist needs. Dent Econ. 2002; 92(4):84-9.

7. Hanson SL, Pichert JW. Patient Education: the importance of instructional time and active patient involvement. Med Teach. 1985; 7(34):313-22.

8. Hood K. Exploring Learning Styles \& Instruction [Online]. 2004 [cited 2005]. Available from http://wilson.coe.uga.edu/emt705.EMT705. Hood.html

9. Gropper G. Instructional Strategies. New Jersey: Education Technology Publication; 1974. pp. 69-74.

10. Lorenz RA, Pichert JW, Boswell EJ, Jamison RN, Schlundt DG. Training health profession students to be effective patient teachers. Med Teach. 1987; 9(4):403-8.

11. Gagne RM. Essentials of Learning for Instruction. Illinois: Dryden Press; 1974.

12. Ferris RT, Winslow EK. Reinforcing desired behavior with periodontal patients. Dent Clin North Am. 1970; 14(2):279-85.

13. Bandaranayake RC. How to plan a medical curriculum. Med Teach. 1985; 7(1):7-13.
14. Fraenkel J, Wallen N. How to Design and Evaluate Research in Education. New York: McGrawHill; 2003.

15. Patton M. How to Use Qualitative Methods in Evaluation. USA: SAGE Publications; 1987.

16. Anderson L, Krathwohl D, Airasian P, et al. A Taxonomy for Learning, Teaching and Assessing. United States: Addison Wesley Longman, Inc.; 2001. pp. 66-69. 